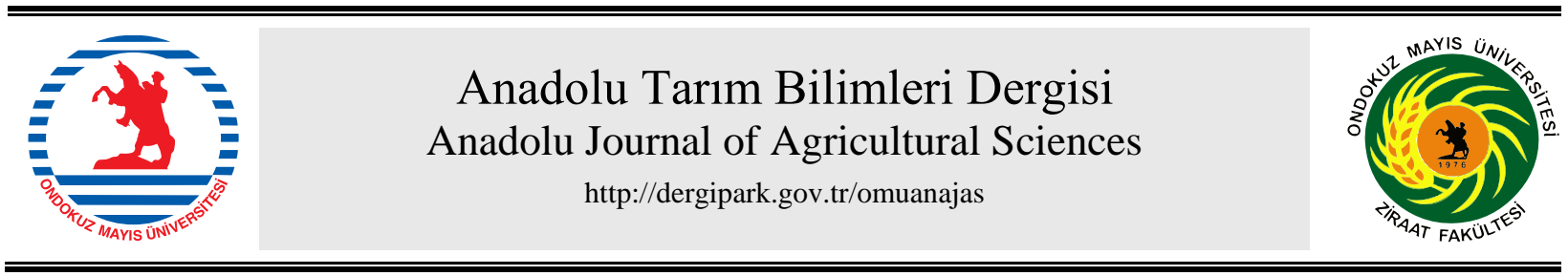

Araştırma/Research

Anadolu Tarım Bilim. Derg./Anadolu J Agr Sci, 35 (2020)

ISSN: 1308-8750 (Print) 1308-8769 (Online)

doi: 10.7161/omuanajas.753302

\title{
Farklı Ana Materyal Üzerinde Oluşmuş Toprakların Fiziko-kimyasal ve Besin Elementi İçeriklerinin Enterpolasyon Yöntemle Değerlendirilmesi
}

\author{
Hüseyin Şenol ${ }^{\mathrm{a}}$, Pelin Alaboz $^{\mathrm{a}^{*}}$, $\odot$ Orhan Dengiz ${ }^{\mathrm{b}}$ \\ ${ }^{a}$ Isparta Uygulamalı Bilimler Üniversitesi, Ziraat Fakültesi, Toprak Bilimi ve Bitki Besleme Bölümü-Isparta

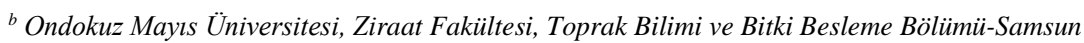 \\ *Sorumlu yazar/corresponding author: pelinalaboz@isparta.edu.tr
}

Geliș/Received 15/06/2020 Kabul/Accepted 21/09/2020

\begin{abstract}
ÖZET
$\mathrm{Bu}$ çalışmada; Afyon - Sandıklı ilçesinde farklı ana materyal üzerinde oluşmuş yüzey toprak örneklerinin fiziko-kimyasal özellikleri belirlenmiş, ters mesafe ağırlıklı enterpolasyon (IDW) yöntemi aracılığıyla konumsal dağılım haritaları oluşturulmuştur. Farklı ana materyal üzerinde oluşmuş toprakların durumlarının değerlendirilmesi amacıyla yapılan çalışmada; kireçtaşı ana materyali üzerinde yer alan toprakların pH'sı hafif alkalin, kireç içerikleri yüksek, mikro element içerikleri ise noksanlık seviyelerinde belirlenmiştir. Genellikle orta-ince tekstür grubu içerisinde olan toprakların özelliklerindeki varyasyon yüksek seviyelerde belirlenmiştir. Tüf ve andezit ana materyal üzerinde oluşmuş toprakların kil, kireç ve Ca içeriği düşük seviyelerde tespit edilmiştir. Eğimli ve zayıf mera alanlarında organik madde oranı orta ve az düzeylerde iken en düşük organik madde, çamurtaşı, kumtaşı ve çakıltaşı ana materyallerin parçalanma-ayrışması ile meydana gelen alüvyonlarda belirlenmiştir. Alüvyon ana materyal üzerinde oluşmuş toprakların potasyum içeriği ise çoğunlukla tarım alanlarında yeterli, eğimli alanlarda ise daha düşük seviyelerde bulunmuştur. Ayrıca bazalt ve volkanit ana materyal üzerinde oluşmuş topraklarda ise mikro element yeterli seviyelerde tespit edilmiştir. Çalışma sonucunda makro ve mikro elementlerin dağılımının ana materyalin çeşidi ve arazi kullanımı/arazi örtüsünden önemli ölçüde etkilendiği belirlemişlerdir.
\end{abstract}

\section{Evaluation of The Physico-chemical and Nutrient Elements Status of Soils Formed on Different Parent Materials Using Interpolation Method}

\section{ABSTRACT}

In this study; the physico-chemical and nutrient elements of the surface soil samples formed on different parent materials in the Afyon - Sandıklı district were determined, and spatial distribution maps were created through the interverse distance weighted interpolation (IDW) method. In the study conducted to evaluate the condition of the soils formed on different materials; The soil reaction of the soils on the limestone parent material is slightly alkaline, the lime content was high, and the micro element contents were determined at the deficiency levels. The variation in the properties of soils, which are generally in the moderate-fine texture group, was determined at high levels. Clay, lime and Ca content of soils formed on tuff and andesite parent material were found at low levels. While the rate of organic matter in the sloping and weak pasture areas was moderate and low, the lowest organic matter was determined in the mudstone, sandstone and conglomerate parent materials that alluviums occur with their disintegration-decomposition. The potassium content of the soils formed on the alluvium parent material was found to be at a sufficient level in agricultural areas and at a lower level in inclined areas. In addition, in the soils formed on basalt and volcanite parent material, micro elements were determined at sufficient levels. As a result of the study, they determined that the distribution of macro and micro elements was significantly affected by the type of parent material and land use/land cover.
Anahtar Sözcükler: Ana materyal Toprak özellikleri Besin elementi Konumsal dağılım

Keywords:

Parent material

Soil properties

Nutrient

Spatial distribution

(C) OMU ANAJAS 2020 


\section{Giriş}

Günümüzde, artan nüfusun bir taraftan fazla ve kaliteli ürün elde etme baskısı oluşturması diğer taraftan gelişen sanayileşmeyle birlikte tarımsal arazilerin amaç dışı kullanımı, verimli toprakların giderek azalmasına yol açmaktadır. Toprak verimliliği ve bitki gelişimini önemli düzeyde etkileyen toprağın fiziksel ve kimyasal özelliklerinin değişimleri büyük oranda toprak oluşturan faktörlerin etkilerine göre şekillenmektedir. Sürdürülebilir tarımsal arazi kullanımları için toprakların tarımsal uygulamalardan ve ekolojik değişimlerden kaynaklanan etkileşimlerini iyi izlemek gerekmektedir. Toprak oluşumu kayaların veya herhangi bir gevşek materyalin parçalanması, ayrışması ile başlar ve çevre koşulları ile dinamik dengeye ulaşıncaya kadar devam eder (Simșek, 2000). Herhangi bir zamanda yapılan mineralojik veya kimyasal analizler toprak oluşturan faktörlerin ana materyal üzerinde etkisinin göstergesidir. Zamana bağlı olarak başlangıç materyalinden fiziksel ve kimyasal olarak önemli derecede farklı özellikler ve değişen yaşlara sahip topraklar meydana gelir. Yağış ve sıcaklık kimyasal, fiziksel ve biyolojik ayrışmanın tipini ve miktarını belirleyen en önemli unsurlardandır (Dahlgren ve ark., 1997; Birkeland, 1999). Bu faktörlerin sabit olduğu alanlarda toprakların farklı özellikler göstermesi diğer toprak oluşturan faktörlerin değişimine bağlıdır.

Birçok çalışmada, farklılaşan toprak oluş faktörlerine göre toprak özelliklerinde değişimlerin olduğu belirlenmiştir (Davies, 1995; Rishirumuhirwa 1997; Okalebo ve ark., 2006; Syldie, 2017). Pal ve ark. (2014), farklı ana materyallerden oluşmuş kırmızı renkli topraklarda, demir ve alüminyumu toksik $\mathrm{N}, \mathrm{P}$ ve $\mathrm{K}$ 'y1 yetersiz seviyede belirlerken, Hauser ve Billing (2017), parçalanma ayrışma derecesinin ileri düzeyde olduğu profillerde organik maddenin, daha hızlı parçalandığını tespit etmiştir. Benedetti ve ark. (2011), bazalt ya da alüviyal etkinin olduğu alanlarda yüksek baz saturasyonu ve kaolinit ile birlikte 2:1 tipi kil minerallerinin varlığını bildirirken, Araujo ve ark., (2014) farklı ana materyal üzerinde oluşmuş toprakların ileri derecede ayrışmasına bağlı olarak ana kayanın Fe, $\mathrm{Al}$ ve Si içeriği ile toprakların diğer özellikleri arasında önemli bir ilişki olmadığını belirtmiştir. Ekberli ve Dengiz (2017) bazalt ana materyali ve farklı topografik pozisyonlar üzerinde oluşmuş toprakları inceledikleri çalışmada; yamaç arazilerde yer alan toprakları Lithic Ustorthent alt grubunda, düz düze yakın eğimli taban ve tepe üstü/plato düzlüklerinde yer alan topraklar ise Typic Haplustert sınıfında belirlemişlerdir. Yarı kurak şartlarda trakit/trakiandezit ana materyal üzerinde oluşan topraklar üzerinde çalışan Şenol ve ark. (2014) makro elementler ve kil mineralojisindeki değişimlerin kısa mesafede bakı ve eğimin ayrışmaya olan etkisinden kaynaklandığını bildirmiştir. Literatürlerden de anlaşıldığı gibi özellikle tarımsal arazi olarak değerlendirilecek alanların verimlilik durumlarının incelenmesi ve uygunluğunun araştırılması aşamasında farklı özelliklere sahip ana materyal kaynağının bilinmesi oldukça önemlidir.

Toprak verimliliği ile doğrudan ilişkili olan toprak parametrelerinin kısa mesafelerde gösterdiği değişimlerin belirlenebilmesinde geleneksel analiz yöntemleri zaman ve maliyet açısından önemli güçlükler yaratmaktadır. $\mathrm{Bu}$ amaçla enterpolasyon yöntemlerle dağılımlarının değerlendirilmesi, toprak verimliliğini etkileyen tüm değişken süreçlerinin takip edilmesi, belirlenmesi, yorumlanması ve etkili bir yönetim biçimi geliştirebilmek açısından oldukça önemlidir. Toprak özelliklerinin farklı enterpolasyon yöntemler kullanılarak yüksek doğruluk ile dağılım haritalarının oluşturulabileceği birçok çalışmada ortaya konmuştur (Özyazıcı ve ark., 2016; Tunçay ve ark., 2018; Dengiz ve ark., 2019; Aydın ve Dengiz, 2019; Celilov ve Dengiz, 2019). Söz konusu bu uygulamaların kullanımıyla bölgenin genel durumunun değerlendirilmesi, sürdürülebilir bir toprak yönetimi için oldukça önemli olarak düşünülmektedir. Bu çalışmada; Afyon ili sandıklı ilçesinde bulunan benzer iklim etkisi altında farklı ana materyal üzerinde oluşmuş olan toprakların fiziko-kimyasal özellikleri ve besin elementlerinin enterpolasyon yöntemler ile değerlendirilmesi amaçlanmıştır.

\section{Materyal ve Yöntem}

\section{1 Çalışma alanı}

Çalışma alanı, Afyon il sınırları içerisinde Sandıklı merkez ve çevresini içeren 1019 m ile 1544 m arasındaki yüksekliğe sahip 11268 ha alanı kaplayan, batıdan doğuya doğru taban araziden tepelik ve dağlık bir topografya sergilemektedir (Şekil 1). Bu alan içerisinde yer alan taban arazilerin dağılımı oldukça geniş yer kaplamaktadır. Bölgenin \% 48.37'i tarımsal alan \% 49.79'lik kısmı orman ve yarı doğal alanlar \% 1.58 'i yapay bölge ve \% 0.26 's1 ise su kütlelerini oluşturmaktadır (Corine, 2018). Çalışma alanına ait iklim verileri uzun yıllara $(1960$ - 2018) ait Afyonkarahisar (Şuhut) Meteoroloji istasyonu rasat verilerine göre, y1llık ortalama sicaklık $10.8{ }^{\circ} \mathrm{C}$, yıllık yağış $362.40 \mathrm{~mm}$, yıllık buharlaşma $663.08 \mathrm{~mm}$ 'dir. Toprak sicaklık rejimi "Mesic", toprak nem rejimi ise "Xeric" altgrup olarak "Dry Xeric" olarak belirlenmiştir (Van Wambeke, 2000). Çalışma alanı 1/100.000 ölçekli toprak haritasında genel olarak işlemeli tarıma uygun olmayan veya sınırlı olarak uygun olan arazilerle orman rejimindeki arazi sınıfına girmiş olsa da alanın büyük bir kısmı tarıma açılmış ve halen tarım yapılmaktadır. Belirtilen alan genel olarak kuru tarımın yoğun olduğu, çok az bir kısmını ise birinci derce önemli tarım arazi sınıfına girdiği belirtilmiştir (KGM, 1994). Alanın temelinde Paleozoyik yaşlı çeşitli şist ve metakuvarsitlerden meydana gelen metamorfik kayaçlar 
bulunur (Şekil 1). Metamorfik kayaçlar Öngür (1973) tarafindan "Afyon Paleozoyik Grubu" olarak adlandırılmıştır. Temelde yer alan bu metamorfik kayaçların üzerinde, Mesozoyik dönemde çakıl taşı, kumtaşı, silt taşı gibi kırıntılı ve dolomitik kireçtaşı, kireçtaşı gibi kimyasal sedimanter kayaçlar uyumsuz olarak yer alırlar. Birim Karatepe, Dere alanı ve Akdağ formasyonlarının parçalanma-ayrışma ürünlerinin temelini oluşturur. Karatepe Formasyonu Afşin (1991), Dere alanı formasyonu Çakmakoğlu (1986) ve Afşin (1991) ve Akdağ formasyonu Öztürk (1981) ve Afşin (1991) tarafindan adlandırılmıştır. Söz konusu bu alandan ana kaya-ana materyal, arazi şekli-topografya ve arazi kullanım-arazi örtüsü farklılıkları göz önünde bulundurularak merkez ve çevresinden olmak üzere 23 noktada yüzey toprak örneklenmesi yapılmıştır.
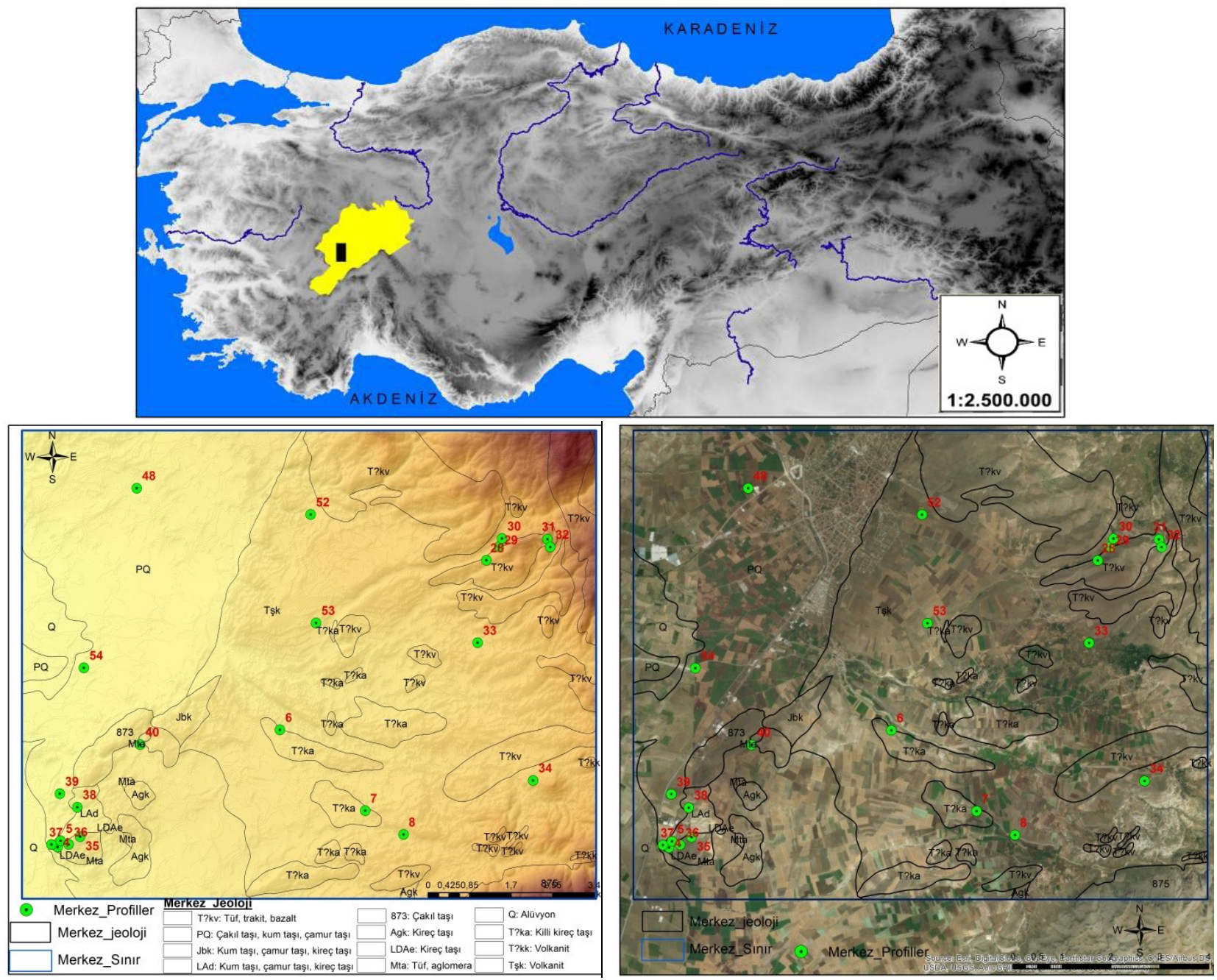

Şekil 1. Çalışma alanı, uydu görüntüsü ve jeolojisi

Figure 1. Study area, satellite view and geology

\subsection{Toprak Analizler}

Araziden getirilen toprak örnekleri, taş ve çakıllardan temizlenerek $2 \mathrm{~mm}$ 'lik veya $0.5 \mathrm{~mm}$ 'lik elekten geçirilerek bazı toprak fiziksel ve kimyasal özellikleri belirlenmiştir. Tane büyüklük dağılımı hidrometre yöntemi ile (Bouyoucus, 1951) topraklara ait $\mathrm{pH}$ ve EC, saturasyon çamurunda (Anonymous, 1954), Kireç içerikleri, $\mathrm{CaCO}_{3}$ eşdeğerleri olarak Scheibler kalsimetresi ile volumetrik metotla (Hizalan ve Ünal, 1966), organik madde belirlemesi, değiş̧irilmiş

Walkley-Black yöntemine göre (Jackson, 1958), Değişebilir katyonlar $\left(\mathrm{Mg}^{++}, \mathrm{Ca}^{++}, \mathrm{Na}^{+}\right.$ve $\left.\mathrm{K}^{+}\right)$, amonyum asetat ile mikro besin elementler $(\mathrm{Fe}, \mathrm{Cu}, \mathrm{Zn}$, $\mathrm{Mn})$ ise DTPA ile ekstrakte edilerek atomik absorbsiyon spektrofotometresinde belirlenmiştir (Kacar, 2009). Toprak özelliklerine ait ele alınan parametrelerin eşik düzeylerini belirlemek amacıyla bazı literatürlerden (Lindsay ve Norvell, 1978; FAO, 1990; Moran ve ark. 2000; Arshad ve Martin, 2002; Boruvka ve ark. 2005; Hazelton ve Murphy, 2007) yararlanılmış ve Çizelge 1'de belirtilmiştir. 
Çizelge 1. Bazı toprak özelliklerine ait eşik değerler

Table 1. Threshold values for some soil properties

\begin{tabular}{|c|c|c|c|c|c|c|}
\hline \multirow{2}{*}{ Parametreler } & \multirow{2}{*}{ Birim } & \multicolumn{5}{|c|}{ Sinıf } \\
\hline & & Fazla & Yeterli & Orta & Az & Çok az \\
\hline \multicolumn{7}{|c|}{ Yarayışlı Makro Element } \\
\hline $\mathrm{N}$ & $\%$ & $>0.32$ & $0.17-0.32$ & $0.09-0.17$ & $\begin{array}{c}0.0045- \\
0.09\end{array}$ & $<0.0045$ \\
\hline $\mathrm{P}$ & $\mathrm{mg} \mathrm{kg}^{-1}$ & $>80$ & $25-80$ & $8.0-25$ & $2.5-8.0$ & $<2.5$ \\
\hline $\mathrm{K}$ & $\operatorname{cmol}(+) \mathrm{kg}^{-1}$ & $>2.56$ & $0.74-2.56$ & $0.74-0.28$ & $0.13-0.28$ & $<0.13$ \\
\hline $\mathrm{Ca}$ & $\operatorname{cmol}(+) \mathrm{kg}^{-1}$ & $>50$ & $17.5-50$ & $5.75-17.5$ & $1.19-5.75$ & $<1.19$ \\
\hline $\mathrm{Mg}$ & $\operatorname{cmol}(+) \mathrm{kg}^{-1}$ & $>12.5$ & $4.0-12.5$ & $1.33-4.0$ & $0.42-1.33$ & $<0.42$ \\
\hline \multicolumn{7}{|c|}{ Yarayışlı Mikro Element } \\
\hline Mn & $\mathrm{mg} \mathrm{kg}^{-1}$ & $>170$ & $50-170$ & $14-50$ & $4-14$ & $<4$ \\
\hline $\mathrm{Zn}$ & $\mathrm{mg} \mathrm{kg}^{-1}$ & $>8.0$ & $2.4-8.0$ & $0.7-2.4$ & $0.2-0.7$ & $<0.2$ \\
\hline $\mathrm{Fe}$ & $\mathrm{mg} \mathrm{kg} \mathrm{kg}^{-1}$ & $>4.5$ & $2.0-4.5$ & $1.0-2.0$ & $1.0-0.2$ & $<0.2$ \\
\hline $\mathrm{Cu}$ & $\mathrm{mg} \mathrm{kg}^{-1}$ & $>0.2$ & - & - & - & $<0.2$ \\
\hline \multicolumn{7}{|c|}{ Kimyasal Özellikler } \\
\hline & & Çok fazla & Fazla & Yeterli & Orta & $\mathrm{Az}$ \\
\hline $\mathrm{CaCO}_{3}$ & $\%$ & $>20$ & $15-20$ & $5-15$ & $1-5$ & $0-1$ \\
\hline & & Çok Tuzlu & Tuzlu & Orta tuzlu & Hafif & Tuzsuz \\
\hline Tuz / EC & $\% / d S m^{-1}$ & $>0.65 />8$ & $\begin{array}{l}0.50-0.65 \\
\quad / 6-8\end{array}$ & $\begin{array}{c}0.15-0.30 \\
/ 2-4\end{array}$ & $\begin{array}{c}0.30-0.50 / \\
4-6\end{array}$ & $\begin{array}{c}0-0.15 / \\
0-2\end{array}$ \\
\hline \multirow{2}{*}{$\mathrm{pH}$} & \multirow{2}{*}{$\begin{array}{l}1: 2,5 \\
(w / v)\end{array}$} & $\begin{array}{l}\text { Hafif asit/hafif } \\
\text { alkalin }\end{array}$ & Alkalin & Asit & $\begin{array}{l}\text { Kuvvetli } \\
\text { asit }\end{array}$ & $\begin{array}{c}\text { Çok kuvvetli } \\
\text { asit/kuvvetli alkali }\end{array}$ \\
\hline & & $6.5-7.5$ & 7.5-8.5 & $5.5-6.5$ & 4.5-5.5 & $<4.5->8.5$ \\
\hline OM & $\%$ & $\begin{array}{c}\text { Fazla } \\
>3\end{array}$ & $\begin{array}{l}\text { Yeter } \\
2-3\end{array}$ & $\begin{array}{c}\text { Orta } \\
1-2\end{array}$ & $\begin{array}{c}\mathrm{Az} \\
0.5-1\end{array}$ & $\begin{array}{l}\text { Çok az } \\
0-0.5\end{array}$ \\
\hline
\end{tabular}

\subsection{Tanımlayıcı istatistikler ve konumsal dağılım haritalarının oluşturulması}

Toprak özelliklerinin tanımlayıcı istatistikleri Minitap 16 paket programı aracıllğıyla değerlendirilmiştir. Çalışma alanı içerisinde dağılım gösteren topraklara ait bazı fiziko-kimyasal özellikleri ait konumsal dağılım haritaları oluşturmak amaciyla bilimsel çalışmalarda en yaygın olarak kullanılan enterpolasyon modellerden birisi olan Ters Mesafe Ağırlıklı Enterpolasyon (IDW) kullanılmıştır (Achilleos, 2011; Taşan ve Demir, 2017; Li ve ark., 2018; Özdemir ve ark, 2019). Bu modelin esası değeri bilinen noktadan değeri bilinmeyen nokta değerini tahmin etmeye dayanmaktadır. $\mathrm{Bu}$ değerin hesaplanmasinda ise uzaklıkların ters mesafe fonksiyonlarından yararlanmaktadır. $\mathrm{Bu}$ varsayım değeri bilinen noktadan hedeflenen noktaya olan uzaklık arttıkça benzerliklerin azaldığı mantığına dayanmaktadır (Shepard, 1968; Li ve Heap, 2008). IDW yönteminde enterpolasyon fonksiyonu aşağıdaki gösterilen eşitlik kullanılarak hesaplanmaktadır (Eşitlik 1).

$$
\lambda i=\frac{1 / d_{i}^{p}}{\sum 1 / d_{i}^{p}}
$$

Eşitlikte di, $\mathrm{x} 0$ ve xi noktaları arasındaki mesafeyi, $\mathrm{p}$ üssel parametre ve $n$ örnek sayısıdır.

\section{Bulgular ve Tartışma}

Çalı̧̧ma alanı içerisinde yer alan jeolojik patternin yükselti ve eğime olan dağılım özelliği Şekil 2'de verilmiştir. Alanın batı, güney batı ve kuzey batı kesimlerini 1019 ile 1107 m yükseltiye sahip olan çakıl taşı, kum taşı ve çamur taşı ana materyale sahip düz, düze yakın eğimli taban araziler oluşturmaktadır. $\mathrm{Bu}$ alanlar çoğunlukla tarım arazileri olarak değerlendirilmektedir. Buna karşın güney, güney doğu ve kuzey doğu ile eğimin arttığı dik yamaçların olduğu, çoğunlukla tüf, trakit, bazalt gibi volkanik ana kayalarının yanı sıra 1107 ve 1194 metrelerde yer yer killi kireçtaşları bulunmaktadır. $\mathrm{Bu}$ alanlar ise çoğunlukla mera arazileri oluşturmaktadır. 
Toprakların tanımlayıcı istatistikleri Çizelge 2'de belirtilmiştir. Toprakların \% 39.13'ü CL, \% 8.69'u L, \% 17.39'u C, \% 13.04'ü SCL, \% 21.73'ü SL bünye grubu içerisinde belirlenmiştir. Wilding (1985)' e göre toprak özelliklerinden $\mathrm{pH}$ "düşük" (<\% 15) silt, kum "orta" (\%15-35) diğer özellikler "yüksek" (> \% $\quad \%$ 35) varyasyon göstermiştir. Toprak özelliklerinden silt, kum, $\mathrm{pH}, \mathrm{Ca}$ içerikleri normale göre sola çarpık (-), diğer özellikler sağa çarpık (+) bir dağılım göstermiştir. Çarpıklık katsayısı en yüksek normalden en uzak dağılım gösteren özellik $\mathrm{Na}$ olarak belirlenmiştir. Toprakların stabil özellikleri dinamik özelliklere göre daha dar bir aralıkta değişmektedir (Wilding ve ark., 1994).
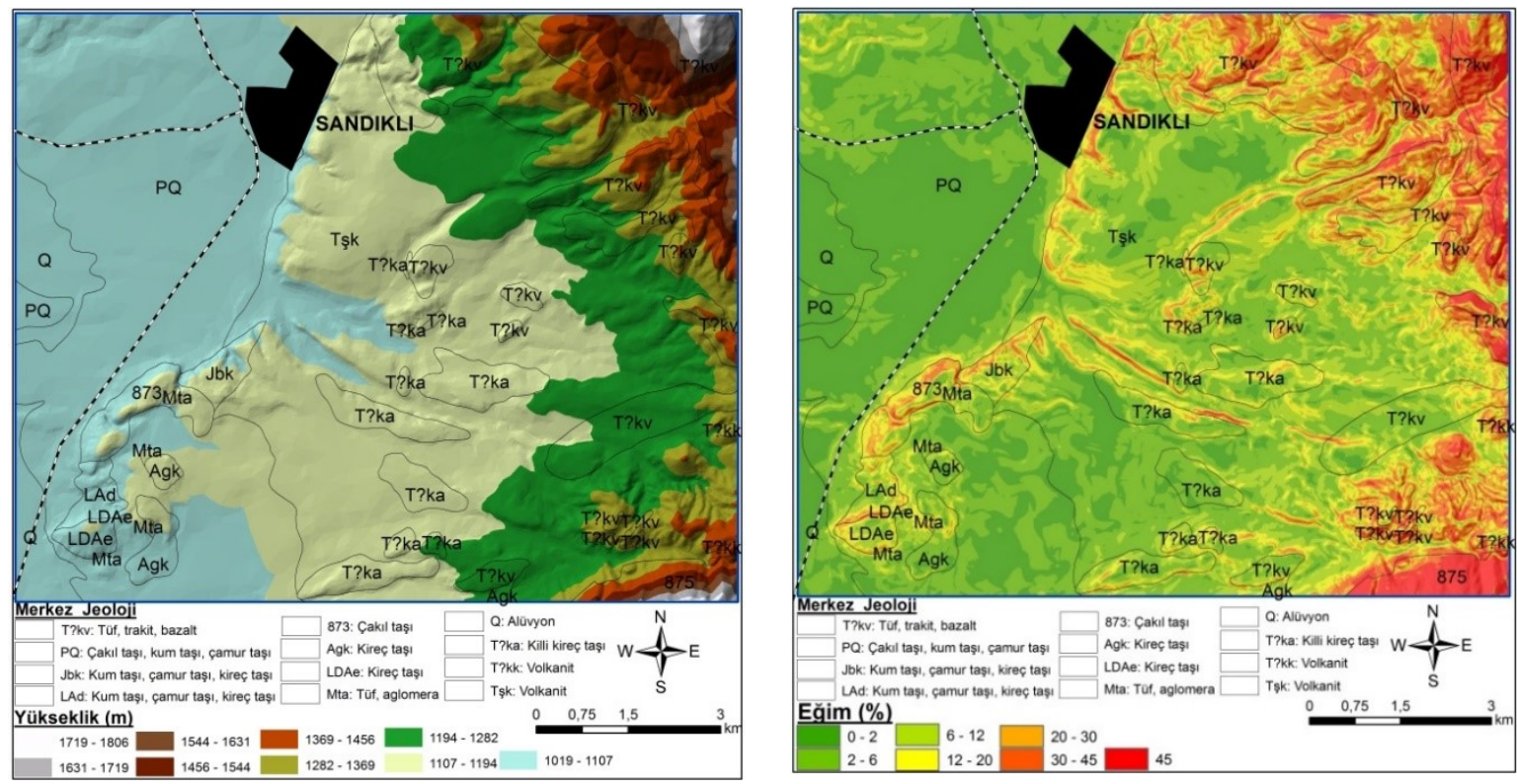

Şekil 2. Yükselti ve eğim haritalarının jeolojik pattern ile birlikte gösterimi Figure 2. Display of elevation and slope maps with geological pattern

Yüzey topraklara ait bünye dağılımları Şekil 3'de verilmiştir. Toprakların kum, silt ve kil içerikleri sirasiyla \% 12.99 - 65.71, 8.29 - 36.64, 8.81 - 68.51 olarak belirlenmiştir. Kil genelde Sandıklı ilçesinin batısında dağılım gösteren çamur taşı ana materyal üzerinde yer alan topraklarda \% 60'lara kadar artış gösterirken bu oran alanın kuzeydoğusundaki tüf ve andezitler üzerinde bulunan topraklarda \% 9'lara kadar azalmaktadır. Alanın orta kesimlerinde bulunan killi kireçtaş1-marn üzerinde ise genellikle \% 25 ile \% 40 arasında değişim göstermektedir. $\mathrm{Bu}$ dağılım ana materyalin, toprakların kil içeriklerine yönelik önemli etki etmiş olabildikleri gibi eğimin ve zayıf bitki örtüsü nedeniyle ince materyallerin taşınması sonucu özellikle eğimin az olduğu taban arazilerde birikmesi nedeniyle de bu alanlarda artmasına neden olabilmektedir. Diğer taraftan kum ise kil dăğllım deseninin tersi durumu sergilemekte olup alanın kuzeydoğu kesimlerdeki tüf, andezit gibi kayaçlar üzerinde yer alan topraklarda kum oranı $\% 60$ düzeylerine ulaşabilmektedir. Ayrıca yer yer çakı1 taşı, kumtaşı gibi alüviyal materyaller üzerinde yer alan topraklarda \%40-50 arasında dağılım gösterebilmektedir. Silt ise, alanın özellikle güney batısında yer alan kireçtaşları üzerindeki topraklarda daha fazla dağılım gösterirken kuzey doğuda yer alan tüfler üzerindeki topraklarda \%8'lere kadar azalmaktadır. 
Çizelge 2. Toprak özelliklerinin tanımlayıcı istatistikleri

Table 2. Descriptive statistics of soil properties

$\begin{array}{cccccccc}\text { Kil } & \text { Ortalama } & \text { Std sap. } & \text { CV } & \text { Min } & \text { Max } & \text { Çarpıklık } & \text { Basıklık } \\ \text { Silt } & 30.85 & 12.85 & 41.66 & 8.81 & 68.51 & 0.78 & 2.23 \\ \text { Kum } & 25.67 & 7.11 & 27.70 & 8.29 & 36.64 & -0.42 & 0.07 \\ \mathbf{p H} & 43.48 & 12.71 & 29.24 & 12.99 & 65.71 & -0.05 & 0.17 \\ \mathbf{E C} & 7.62 & 0.32 & 4.31 & 6.92 & 8.30 & -0.22 & -0.08 \\ \mathbf{O M} & 0.14 & 0.12 & 87.48 & 0.04 & 0.67 & 3.70 & 15.85 \\ \mathbf{C a C O _ { 3 }} & 2.41 & 1.030 & 42.73 & 1.06 & 4.48 & 0.78 & -0.53 \\ \mathbf{P} & 15.82 & 17.83 & 112.69 & 3.83 & 55.86 & 1.45 & 0.33 \\ \mathbf{C a} & 10.03 & 4.50 & 44.86 & 3.04 & 19.43 & 0.27 & -0.72 \\ \mathbf{M g} & 28.67 & 13.82 & 48.19 & 5.39 & 49.42 & -0.58 & -1.22 \\ \mathbf{K} & 3.10 & 2.94 & 94.69 & 0.34 & 9.895 & 1.36 & 0.92 \\ \mathbf{N a} & 0.74 & 0.45 & 61.27 & 0.16 & 1.84 & 1.06 & 0.76 \\ \mathbf{F e} & 0.10 & 0.11 & 112.03 & 0.01 & 0.55 & 3.23 & 12.31 \\ \mathbf{C u} & 14.66 & 9.19 & 62.70 & 4.42 & 36.71 & 1.08 & 0.47 \\ \mathbf{Z n} & 1.65 & 0.81 & 49.45 & 0.40 & 3.424 & 0.62 & -0.36 \\ \mathbf{M n} & 1.39 & 1.51 & 108.21 & 0.29 & 6.045 & 1.99 & 3.51 \\ \mathbf{M n} & 77.40 & 63.70 & 82.36 & 15.30 & 251.90 & 1.29 & 1.09\end{array}$

EC: elektriksel iletkenlik, OM: organik madde, $\mathrm{CaCO}_{3}$ kireç, P: fosfor, Ca: kalsiyum, Mg:Magnezyum, K:potasyum, Na: sodyum, Fe: Demir, Cu: bakır, Zn:çinko, Mn:mangan, Std sap:standart sapma, CV:varyasyon katsayısı, Min:Minimum, Max:maksimum

Toprakların kireç içeriklerine yönelik dağılım haritası Şekil 3'de verilmiştir. Toprakların kireç içerikleri \% 3.83-55.86 arasında orta-çok fazla sınıfları içerisinde belirlenmiştir. Şekil 3'de görüleceği üzere toprakların kireç içeriklerindeki artış veya azalışındaki eğilim, toprakların üzerinde oluştukları ana materyalleri kireç içerikleri ile yakından ilişkilidir. Alanın güney batısında çoğunlukla dağılım gösteren LDAe ve Agk kodlu kireçtaşları üzerinde yer alan topraklarda kireç \% 55'lere kadar çıkmaktadır. Buna karşın, Sandıklı ilçesinin doğusunda ve eğimli arazilerde yer alan tüf, bazalt ve andezit üzerindeki topraklarda bu oran \% 4'lere kadar düşmektedir. Kuzey çalışma sahasında belirtildiği gibi bu ana materyaller normalde karbonat içermemelerine karşılık topraklarda az da olsa kireç bulunması gerek ayrışma sonucu açığa çıkan Ca iyonunun, topraktaki karbondioksit ve suyun etkileşmesi sonucu oluşan bikarbonat ile oluşturduğu bileşik sonrasinda sekonder olarak meydana gelebilmesinin yanı sıra taşınma sonrası bulaşmadan da kaynaklanabilmektedir. Everest ve Özcan (2018) toprak verimliliğine yönelik pedo-jeolojik yaklaşım konulu çalışmalarında, zeytin tarımı yapılan arazilerin verimlik durumlarının pedo-jeolojik yaklaşım ile belirlenmesini amaçlamışlardır. Elde edilen sonuca göre granit kökenli kayaçların fazla olduğu alanlarda toprak bünyesinin hafif-orta olduğu belirlenmiştir. Çalışma alanında sedimanter kırıntılı malzemelerin bol miktarda olması toprakların \% $\mathrm{CaCO}_{3}$ içeriklerinin yüksek ve $\mathrm{pH}$ değerlerinin hafif alkalin olmasına neden olduğunu belirlemişlerdir.

Toprakların organik madde dağılım haritası Şekil 3 'de verilmiştir. Toprakların organik madde içerikleri \% 1.06 - 4.48 ile az ve fazla sinifları arasinda belirlenmiştir.
Organik maddenin \%3’ü geçtiği alanlar Sandıklı ilçesinin hemen doğusunda yer alan mera alanlarında belirlenirken, en düşük düzeyler (\% 2'nin altında) alanın batısında dağılım gösteren çamurtaşı, kumtaşı ve çakııttaşı ana materyallerin parçalanma-ayrışması ile meydana gelen alüvyonlardır. Q ve PQ ile simgelenmiş ana materyal üzerindeki ve tarımsal faaliyetlerde kullanılan topraklarda belirlenmiştir. Ayrıca çok eğimli ve zayıf mera alanlarında organik madde oranı yine orta ve az düzeylerde olduğu belirlenmiştir. Yeşilırmak teraslarında, alüvyal ana materyal üzerinde oluşmuş toprakların $\mathrm{pH}$ değerleri 7.38-8.41, kireç içerikleri \% 0.8-25.4 arasında değişmiş, organik madde içerikleri ise düşük düzeyde saptanmıştır (Durak ve Aydın, 2014). Toprakların $\mathrm{pH}$ değişkenliklerine yönelik Şekil 3'de dağılım haritası verilmiştir. Toprakların pH'sı 6.928.30 arasındadır. Alanın kuzeydoğu kesimlerinde eğimli arazilerde yer alan ve çoğunluğu tüf, trakit, bazalt gibi volkanitlerin dağılım sergilediği ana kayalar üzerinde yer alan topraklar nötr ve hafif alkalin iken, güney batı kesimlerde ise $\mathrm{pH}$ değerleri 8.3'lere kadar yükselerek hafif alkaliden, alkalin düzeyine kadar çıkabilmektedir. Kireçtaşlarının yoğun olduğu bazı güneybatı kesimlerde ise topraklar 7.5 düzeylerde olup hafif alkalin reaksiyonludur. Toprakların EC dağılımları Şekil 4'de belirtilmiştir. Toprakların EC değerleri $2 \mathrm{dS} \mathrm{m}^{-1}$, den az olup, tuzluluk problemi bulunmamaktadır. Batı kesimlerde yer alan özellikle tarım topraklarda bir miktar artış eğilimi göstermektedir 

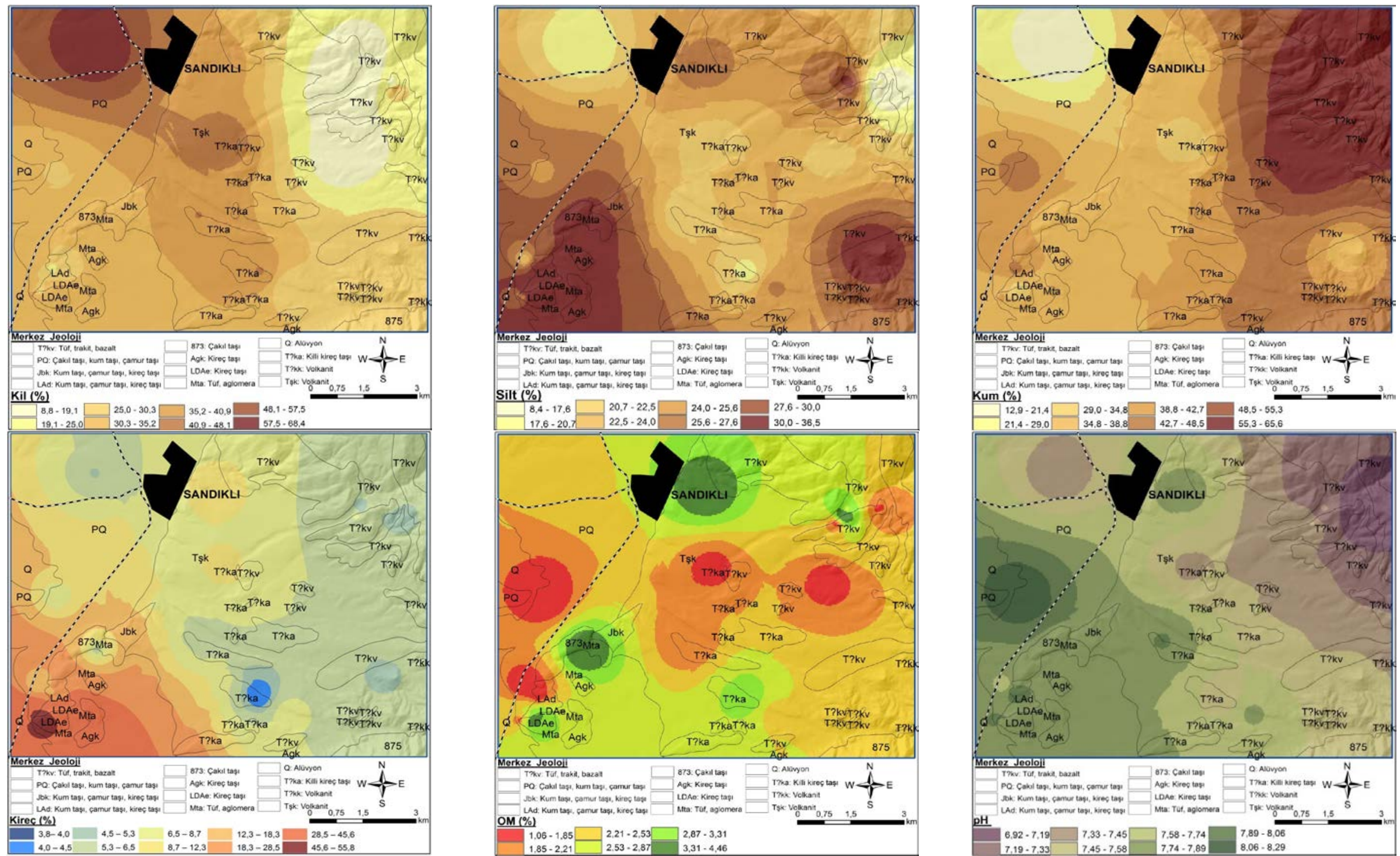

Şekil 3. Toprakların kil, silt, kum, kireç, organik madde ve $\mathrm{pH}$ dağılımı

Figure 3. Clay, silt, sand, lime, organic matter and $\mathrm{pH}$ distribution of soils 
Toprakların değiş̧ebilir bazik katyonlarına ait dağılım haritaları Şekil 4'de verilmiştir. Toprakların çoğu özellikle Sandıklı ilçesinin batı ve güneybatısında dağılım gösteren kireçtaşı ve alüvyon ana materyali topraklarda bazik katyonlar yeterli düzeylerde bulunurken alanın kuzeydoğu kesiminde çoğunlukla tüf ve andezit olan kayaçlar $\mathrm{Ca}$ iyonunca fakirdirler. $\mathrm{Bu}$ nedenle topraklarda $\mathrm{Ca} 5.4 \mathrm{cmol} \mathrm{kg}^{-1}$ kadar azalmaktadır. Magnezyum iyonu ise oldukça değişkenlik göstermekte olup alanın güney batı kesiminde yer alan kireçtaşı ve alüvyon ana materyalli topraklar ile alanın kuzeydoğu kesiminde dağılım gösteren tüf ve trakit ana materyalli topraklarda az ve çok az düzeylere kadar düşerken $\left(<0.42 \mathrm{cmol} \mathrm{kg}^{-1}\right)$, orta kesimlerde dağılım gösteren çoğunlukla killi kireçtaşı (T?ka) ve PQ simgeyle gösterilen çamurtaşı, kumtaşı, çakıltaşlı ana materyaller üzerinde dağılım gösteren topraklarda yeter düzeylerde olup yaklaşı $10 \mathrm{cmol} \mathrm{kg}^{-1}$, a kadar çıkmaktadır. Yine önemli bir besin elementi olan potasyum ise $(\mathrm{K})$ çoğunlukla tarım alanlarının kapladığı ve alanın batı ve kuzey batısında yer alan alüvyon ana materyal üzerindeki topraklarda yeterli düzeylerde iken, doğu ve kuzeydoğu kesimlerdeki eğimli alanlarda $0.16 \mathrm{cmol} \mathrm{\textrm {kg } ^ { - 1 }}$ düzeyine kadar azalmaktadır. Fakat güney, doğu ve kuzeydoğu kesimlerde genel olarak 0.5 ile $0.7 \mathrm{cmol} \mathrm{kg}^{-1}$ olup orta düzeylerde dağılım sergilemektedir. Tarımsal potansiyeli yüksek değere sahip alüviyal arazilerde taşınıp gelen sedimentlerde oluşan farklılıklardan kaynaklı arazi içerisinde kısa mesafelerde dahi toprakların özelliklerinde farklılıklar belirlenmektedir (Coşkun ve Dengiz, 2016). Kısa mesafelerdeki bu değişkenlik üretim potansiyeli için önemlidir. Sodyum (Na) elementi Mg elementine benzer bir desen sergilemekte olup alanın güney batı ve kuzey doğu kesimlerinde azalmakta orta kesimlerde yayın olarak yer alan alüvyon ve tüf, trakit ana materyaller üzerindeki topraklarda artı̧̧ göstermektedir. Sodyum değerlerindeki fazlalık, ana materyal Trakit olmasına rağmen yüzeysel taşınımla ve tabanda yer alan şistlerden gelen albitlerden kaynaklanabileceği düşünülmektedir. Albit, plajioklas kesiksiz seri içerisinde magmadan oluşum sırasında sıcaklığın azalmasına bağlı olarak NaPlajioklas (Albit, $\mathrm{NaAlSi}_{3} \mathrm{O}_{8}$ ) oluşur. Çalışma alanındaki $\mathrm{Na}$ değerlerindeki yüksek sonuçlar köken kayacın içerisinde yer alan Albit minerali varlığını ortaya koymaktadır. Bu mineralin parçalanma-ayrışması sonrası toprak çözeltisine karışarak $\mathrm{Na}$ yüksek sonuç vermesinde etkin olmuştur.
Toprakların fosfor dağılım haritası Şekil 4'de verilmiştir. Alana ait çoğu topraklarda fosfor $8 \mathrm{mg} \mathrm{kg}^{-1}$ ile $25 \mathrm{mg} \mathrm{kg}^{-1}$ arasında değişmekte olup orta yeterli düzeydedir. Fakat fosfor dağılım trendine bakıldığında Sandıklı ilçe etrafında dağılım gösteren özellikle tarım arazilerinde yaklaşık $19 \mathrm{mg} \mathrm{kg}^{-1}$ seviyelerine kadar çıkarken, güney kesimlerde dağılım gösteren kireçtaşı, killi kireçtaşı ana materyaller üzerinde oluşmuş topraklarda bu değer $3 \mathrm{mg} \mathrm{kg}^{-1}$, a kadar azalmaktadır. Kireçli topraklarda fosfor fiksasyonuna bağlı olarak fosfor içeriğinin düşük olması beklenen bir durumdur (Korkmaz 2005).

Toprakların demir içerikleri ana materyalin içerdiği minerallere bağlı olarak ayrışma sonrası oldukça farklılıklar göstermektedir. Şekil 5'de görüleceği üzere bazalt ve volkanitlerin yoğun olarak dağılım gösterdiği alanın kuzeydoğu alanlarındaki topraklarda demir 37 $\mathrm{mg} \mathrm{\textrm {kg } ^ { - 1 }}$ seviyelerine kadar çıkmaktadır. Buna karşın güneybat1 kesimlerdeki kireçtaşı ve tüf içeren alanlardaki topraklarda bu oran yaklaşık $4.5 \mathrm{mg} \mathrm{kg}^{-1}$ kadar azalmaktadır. Bitkiler açısından sınır değerlere bakıldığında ise topraklarda demir eksikliği bulunmamaktadır. Demir içeriklerinin yüksek çıkmasında magmatik köken kayaç içerisindeki biyotit mineralinin parçalanma-ayrışma etkinliğidir. Çinko ise özellikle tarım yapılan alüviyal araziler üzerinde yer alan topraklar ile kireçtaşı, killi kireçtaşları ve tüf gibi ana materyale sahip güney ve orta kesimlerde orta ve az düzeylerde bulunmaktadır. Alanın kuzeydoğu kesimlerdeki bazalt ve volkanitler üzerinde yer alan topraklarda ise yeterli düzeylere ulaşabilmektedir. Alanın tüm jeolojik özellikleri üzerinde dağılım gösteren topraklarda bakır eksikliği belirlenmemiş olup $0.2 \mathrm{mg} \mathrm{kg}^{-1}$ dan fazladır. Fakat $\mathrm{Cu}$ konsantrasyonunun alan içerisindeki dağılım eğilimine bakıldığında, Sandıklı ilçesi ve civarındaki alanlarda yaklaşık $3.4 \mathrm{mg}$ $\mathrm{kg}^{-1}$ kadar çıkabilmektedir. Mangan elementi ise alan içerisinde orta ile fazla düzeyler içerisinde dağılım göstermekte olup 15.4 ile $251.9 \mathrm{mg} \mathrm{kg}{ }^{-1}$ arasinda değişmektedir. $\mathrm{Bu}$ dağılımın en yüksek olduğu alanlar genelde güneybatı kesimlerde dağılım gösteren kireçtaşı ve killi kireçtaşının üzerinde oluşmuş topraklarda bulunmaktadır. Benedetti ve ark. (2011), Pliyopleyistosen sedimanter ve bazik volkanik kayaç üzerinde çayır bitki örtüsü altında topoğrafyanın toprak oluşumu üzerine etkisini araştırdıkları çalışmada; Sedimentlerde verimliliğin düşük, asitliğin yüksek, baskın kaolinit ile birlikte düşük $\mathrm{Fe}$ oksit içeriği; bazalt ya da alüviyal etkinin olduğu alanlarda yüksek baz saturasyonu ve kaolinit ile birlikte 2:1 tipi kil minerallerinin varlığ 


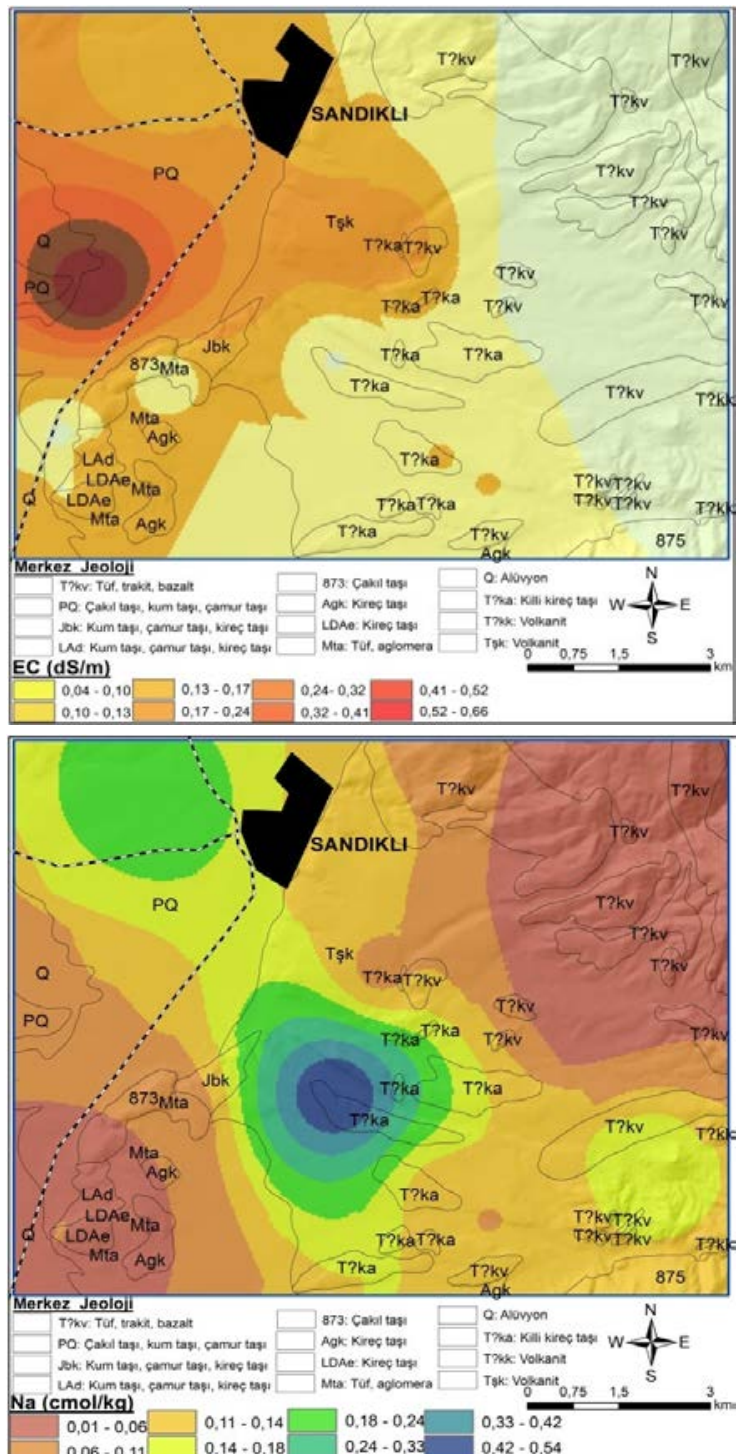

Şekil 4. Toprakların EC, Ca, Mg, Na, K, P dağıılımları Figure 4. EC, Ca, Mg, Na, K, P distributions of soil
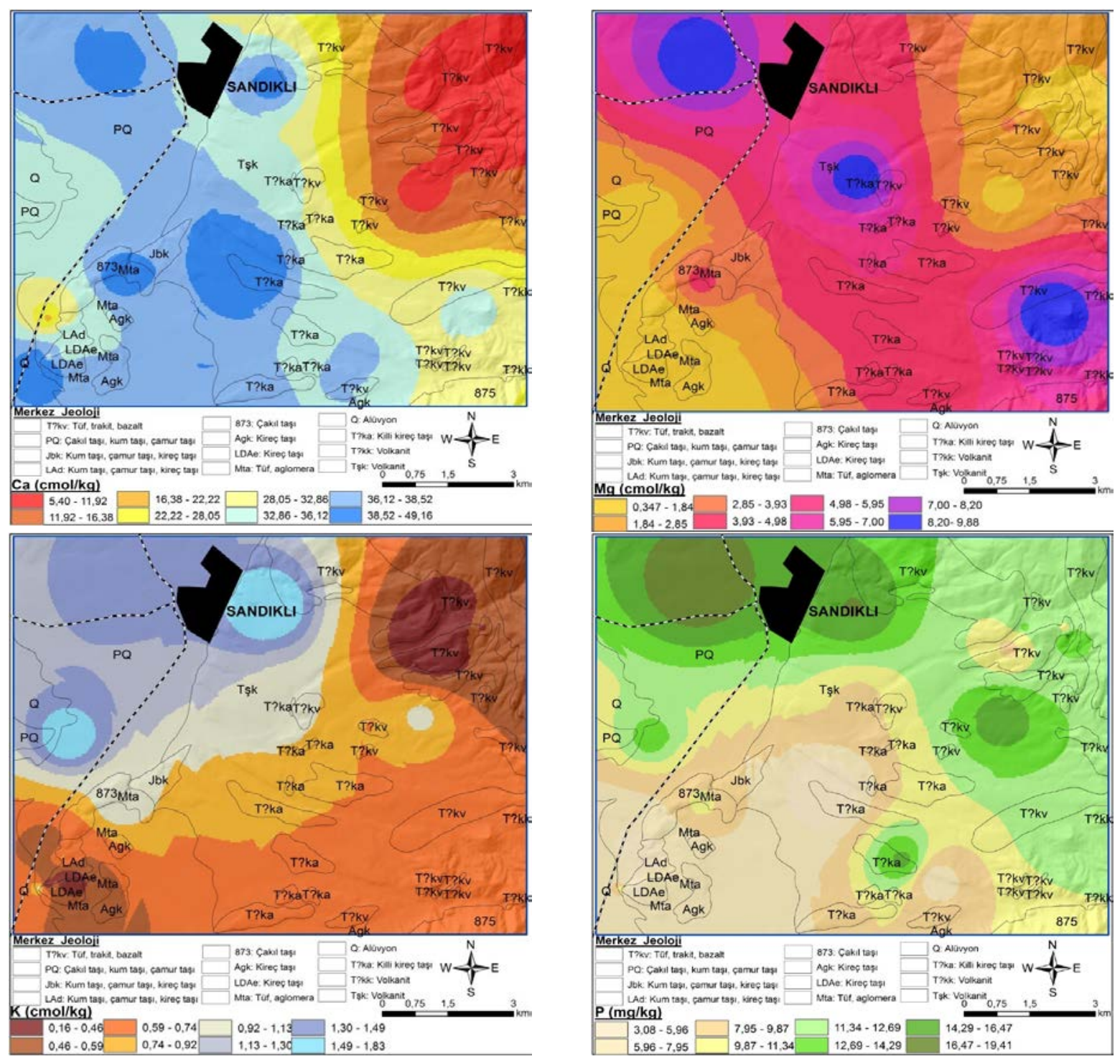


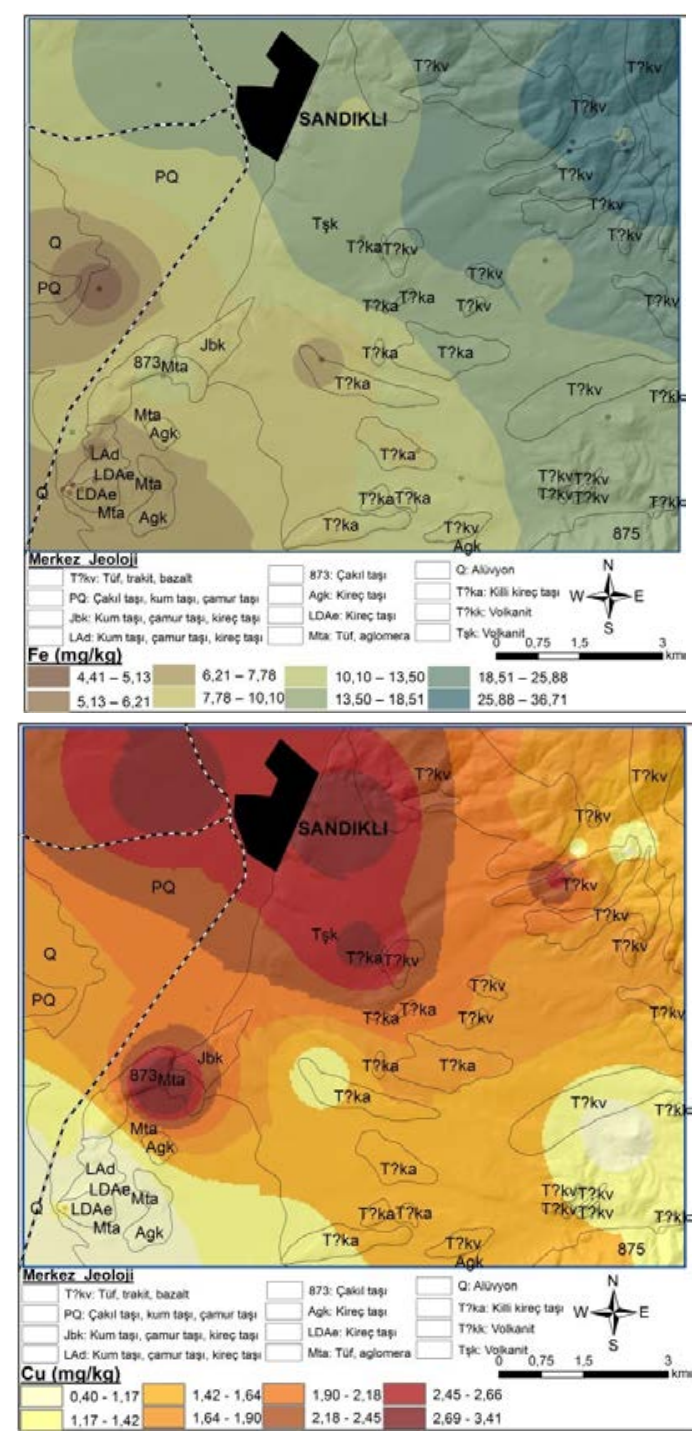

Şekil 5. Toprakların mikro element dağılımları Figure 5. Micro element distributions of soils

\section{Sonuç}

$\mathrm{Bu}$ çalışmada; farklı ana materyal üzerinde oluşmuş olan toprakların fiziko-kimyasal özelliklerindeki değişim incelenmiş, noktasal veriler enterpolasyon yöntemler ile değerlendirilerek konumsal dağılım haritaları oluş̧urulmuştur. Topraklara ait özelliklerin konumsal dağılım haritalarını oluşturmak amacıyla Ters IDW enterpolasyon modeli kullanılmıştır. Çalışma alanı içerisinde eğim ve zayıf bitki örtüsü nedeniyle ince materyallerin taşınması sonucu özellikle eğimin az olduğu taban arazilerde kil birikimleri artmıştır. Tüf ve andezit gibi kayaçlar üzerinde yer alan toprakların kum içerikleri yüksek, çamurtaşı, kumtaşı ve çakıltaşı ana materyallerinde oluşmuş topraklarda ise organik madde seviyesi düşük olarak tespit edilmiştir. Bölgede dağılım gösteren topraklarda tuzluluk problemi görülmemiştir. Tüf ana materyal üzerinde oluşmuş topraklarda mikro, makro elementler ve kil içerikleri düşük seviyelerde bulunurken, kil içerikleri yüksek belirlenmiştir. Kireç

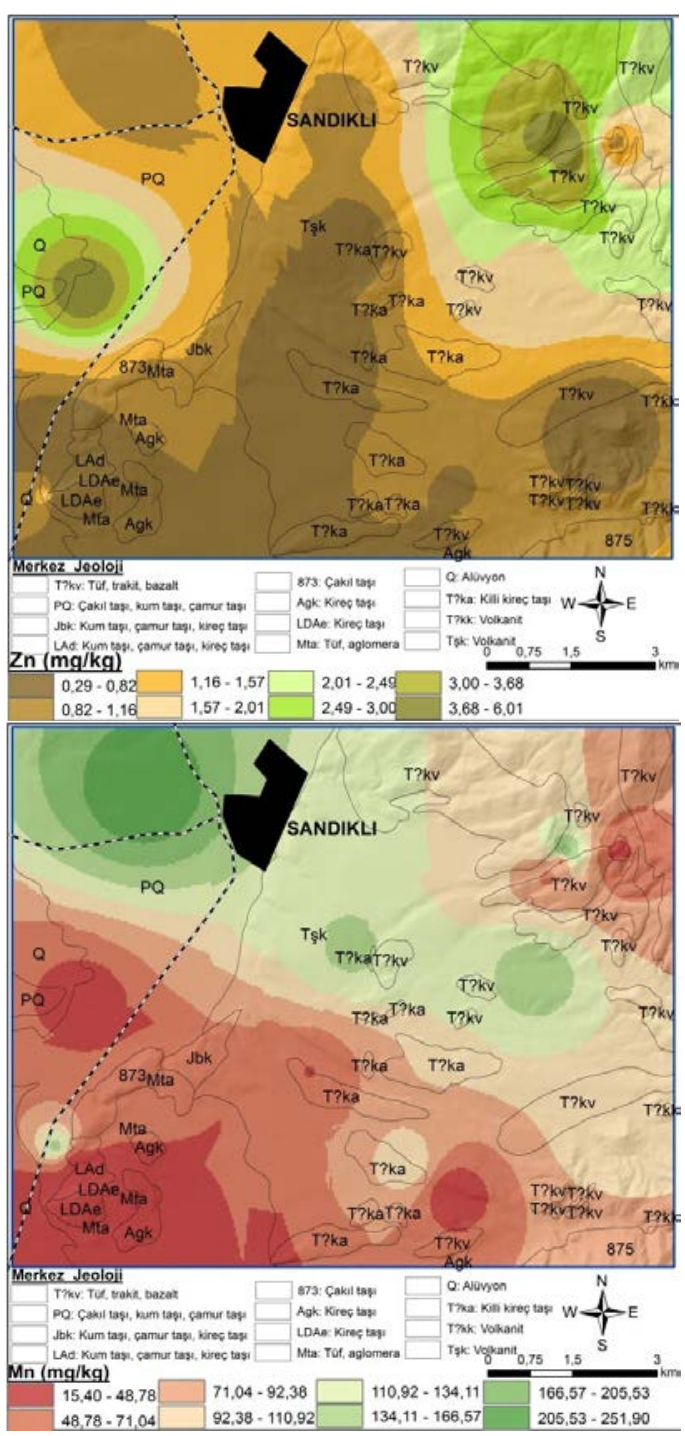

taş1 üzerinde oluşmuş topraklarda demir ve çinko noksanlıkları görülürken trakit ve alüvyonlarda $\mathrm{Na}$ yüksek seviyelerde bulunmuştur. Bölgede Fe noksanlığı görülmezken bazalt ve volkanitler üzerinde oluşan toprakların mikro element içerikleri yeterli seviyede belirlenmiştir.

Çalışma sonucunda; farklı ana materyaller üzerinde oluşmuş toprakların özelliklerinde değişkenliklerin olduğu belirlenmiştir. Söz konusu bu alanda özellikle ana materyale bağlı olarak oluşan toprakların tarımsal amaçlı ne derece kullanıma uygun olduklarına karar verilmeden önce elde edilen bulgular dikkate alınarak değerlendirilmesi önerilmektedir.

\section{Teşekkür}

$\mathrm{Bu}$ çalışma TÜBİTAK tarafindan desteklenen TOVAG $118 \mathrm{O} 282$ No'lu proje kapsamında gerçekleştirilmiştir. Katkılarından dolayı teşekkür ederiz. 


\section{Kaynaklar}

Achilleos, G.A., 2011. The inverse distance weighted interpolation method and error propagationmechanism - creating a DEM from an analogue topographical map. Journal of Spatial Science, 56(2): 283-304.

Afşin, M., 1991. Afyon Sandıklı Kuruçay ovası ve Hüdai kaplıcasının hidrojeoloji incelemesi, Ankara Üniversitesi, Doktora tezi, 330s, Ankara, (yayımlanmamış).

Anonymous, 1954. Diagnosis and improvement of saline and alkali soils. US., Salinity Laboratuary Staff. USDA, Agricultural Handbook, 60.

Araujo, M.A., Pedroso, A.V., Amaral, D.C., Zinn, Y.L., 2014. Mineral assemblage of soils developed from different lithologies in southern Minas Gerais, Brazil. Rev. Bras. Ciênc. Solo [online], 38(1): 11-25.

Arshad, M.A., Martin, S., 2002. Identifying critical limits for soil quality indicators in agro-ecosystems. Agr Econ and Envi, 88: 153-160.

Aydin, A., Dengiz, O., 2019. Determination of physicochemical and nutrient element content of soils formed under semi-humid ecological environment. Akademik Ziraat Dergisi, 8(2): 301-312.

Benedetti, U.G., Do Vale, J.F., Schaefer, C.E.G.R., Melo, V.F., Uchoa, S.C.P., 2011. Genesis, chemistry and mineralogy of soils derived from PlioPleistocene sediments and from volcanic rocks in Roraima North Amazonia. Revista Brasıleıra De Crencia Do Solo, 35 (2):299-312.

Birkeland, P.W., 1999. Soils and Geomorphology. Oxford Univ. Press, New York, 430 pp.

Boruvka, L., Vacek, O., Jehlick, J., 2005. Principle component analysis as a tool to indicate the origin of potentially toxic elements in soils. Geoderma, 128: 289-300.

Bouyoucos, G.J., 1962. Hydrometer method improved for making particle size analyses of soils. Agron. J., 54: 464-465.

Celilov, C., Dengiz, O., 2019. Erozyon duyarlılık parametrelerinin farklı enterpolasyon yöntemleriyle konumsal dağılımlarının belirlenmesi: Türkiye, Ilgaz milli park toprakları. Türkiye Tarımsal Araştırmalar Dergisi, 6(3): 242-256.

Corine, 2018. Corine land use land cover map ofTurkey. Available at https://corinecbs.tarimorman.gov.tr (Erişim tarihi: 23 Mayıs 2020).

Coşkun, A., Dengiz, O., 2016. Samsun terme havzası bazı temel fizyografik karakteristikleri belirlenmesi ve tarımsal taşkın alanlarının toprak haritalanması. Türkiye Tarımsal Araştırmalar Dergisi, 3(1): 1-13.

Çakmakoğlu, A., 1986. Çivril-Banaz-Sandıkl1-Dinar arasındaki bölgenin jeolojisi (K23-c1,c2,c3,c4d3; K24-d3,d4; L23-a2,a3,b1,b2,b3,b4; L24a1,a2,a3,a4). MTA Rap. Derleme No: 8062, Ankara.
Dahlgren, R.A., Boettinger, J.L., Huntington, G.L., Amundson, R.G., 1997. Soil development along an elevational transect in the western Sierra Nevada, California. Geoderma, 78: 207-236.

Davies, G., 1995. Banana and plantain in the East African highlands. In: Gowen SR (ed) Bananas and Plantains: Chapman, Hall, London, UK. 493-508.

Dengiz, O., Saygın, F., İmamoğlu, A., 2019. Spatial variability of soil organic carbon density under different land covers and soil types in a sub-humid terrestrial ecosystem. Eurasian Journal of Soil Science, 8(1): 35-43.

Durak, A., Aydın, M.E., 2014. Yeşilırmak nehir teraslarında toprakların oluşumu ve sınıflandırılması.Türk Tarım-Gıda Bilim ve Teknoloji Dergisi, 2(2): 98-105.

Ekberli, İ., Dengiz, O., 2017. Bazalt ana materyali ve farklı topografik pozisyonlar üzerinde oluşmuş toprakların bazı topografik ve fiziko-kimyasal özellikleri arasındaki doğrusal regresyon modellerinin belirlenmesi. Toprak Su Dergisi, 6(1): 15-27.

Everest, T., Özcan, H., 2018. Toprak verimliliğinin değerlendirilmesinde pedo-jeolojik yaklaşım. Türk Tarım ve Doğa Bilimleri Dergisi 5(4): 589-603.

FAO, 1990. Micronutrient, assessment at the country level: An International Study. FAO Soil Bulletin by Sillanpaa. Rome.

Hauser, E., Billings, S., 2017. Illuminating pathways of forest nutrient provision: relative release from soil mineral and organic pools. American Geophysical Union 2017 Fall Meeting, New Orleans, Louisiana, 11-15 December 2017.

Hazelton, P., Murphy, B., 2007. Interpreting soil test results. What do the numbers mean? Csiro Publishing p152, Australia.

Hizalan, E., Ünal, H., 1966. Topraklarda önemli kimyasal analizler. Ankara Üniversitesi, Ziraat Fakültesi, Yayın No: 278, Ankara.

Jackson, M.L., 1958. Soil Chemical Analysis. P: 498. Prentice-Hall, Inc. Englewood Cliffs, New Jersey. USA.

Kacar, B., 2009. Toprak analizleri. Nobel Yayın Dağıtım, 467s, Ankara.

KGM, 1994. Afyon ili arazi varlığ1 ve arazilerin tarımsal kullanma uygunluğu. Köy Hizmetleri Genel Müdürlüğü, Ankara.

Korkmaz, K., 2005. Kireçli toprakların fosfor durumlarının belirlenmesi ve fosfor uygulamasının mısır verimine etkisi. Yüksek Lisans Tezi. Çukurova Üniversitesi Fen Bilimleri Enstitüsü, 126s Adana.

Li, J., Heap, A.D., 2008. A Review of spatial interpolation methods for environmental scientists. Geoscience Australia, Record 2008/23, 137 pp.

Li, Z., Wang, K., Hao, M., Wu, H., 2018. An adjusted 1nverse distance weighted spatial interpolation method. advances in computer science research. 3rd International Conference on Communications, 
Information Management and Network Security (CIMNS 2018), 128-132.

Lindsay, W.L., Norwell, W.A., 1978. Develepment of a DTPA Soil Test for Zn, Fe, Mn and Cu. Soils Sci. Soc. Am. J., 42: 421-428.

Moran, E.F., Brondizion, E.S., Tucker, J.M., Da SilvaForsberg, M.C., McCracken, S., Falesi, I., 2000. Effects of soil fertility and land use on forest succession in Amazonia. Forest Ecol Manag, 139: 93-108.

Okalebo, J.R., Othieno, C.O.; Woomer, P.L.; Karanja, N.K.; Semoka, J.R.M., Bekunda, M.A., Mugendi, D.N., Muasya, R.M., Bationo, A., Mukhwana, E.J., 2006. Available technologies to replenish soil fertility in East Africa. Nutr. Cycl. Agroecosys, 76:153-170.

Öngür, T., 1973. Sandıklı (Afyon) jeotermal araştırma bölgesine ilişkin jeolojik durum ve jeotermal enerji olanakları. Maden Tetkik ve Arama Genel Müdürlüğü Rapor No;5520, Ankara, (yayımlanmamış).

Özdemir, N., Öztürk, E. Yakupoğlu, T., 2008. Ana materyal ve arazi kullanım şeklinin topraktaki bazı mikroelement fraksiyonlarının dağılımına etkileri, OMÜ Ziraat Fakültesi Dergisi, Samsun, 23 (2): 9297.

Öztürk, A., 1981. Homa-Akdağ (Denizli) yöresinin stratigrafisi. TJK, Bülten, C24S1: 75-84.

Özyazıcı, M.A., Dengiz, O., Aydoğan, M., Bayraklı, B., Kesim, E., Urla, Ö., ... \& Ünal, E., 2016. Orta ve Doğu Karadeniz Bölgesi tarım topraklarının temel verimlilik düzeyleri ve alansal dağılımları. Anadolu Tarım Bilimleri Dergisi, 31(2016): 136-148.

Pal, D.K., Wani, S.P., Sahrawat, K.L., Srivastava, P., 2014. Red ferruginous soils of tropical Indian environments: A review of the pedogenic processes and its implications for edaphology. Catena, 121: 260-278.

Rishirumuhirwa, T., 1997. Rôle du bananier dans le fonctionnement des exploitations agricoles sur les hauts plateaux de l'Afrique centrale. Lausanne, Thèse EPFL No. 1636. 321p.

Shepard, D., 1968. A two-dimensional interpolation function for irregularly-spaced data. Proceedings of the 1968 ACM National Conference. pp. 517-524.

Syldie, B., 2017. Crop yield potential as telltale indice of soil weathering extent and fertility status: The case of East African Highland Bananas. African Journal of Agricultural Research 12 (16): 13621378.

Şenol, H., Özaytekin, H.H., Akgül, M., Alaboz, P. 2014. Yarı kurak şartlarda trakit/trakiandezit ana materyal üzerinde oluşan toprakların ayrışma oranları ve kil mineralojisine bakının etkisi. Journal of Agricultural Sciences, 20: 288-301.

Şimşek, G., 2000. Toprak oluşumu (pedogenesis) ve sınıflama ders notları. Atatürk Üniversitesi, Ziraat
Fakültesi Yayınları Ders Notu, Yayın No: 139. Erzurum.

Taşan, M., Demir, Y., 2017. Çeltik yetiştiriciliği yapılan arazilerde demir ve mangan içeriklerinin alansal dağılımının farklı enterpolasyon yöntemleri ile belirlenmesi. Anadolu Tarım Bilimleri Dergisi, 32: 64-73.

Tunçay, T., Başkan, O., Bayramin, İ., Dengiz, O., Kılıç, Ş., 2018. Geostatistical approach as a tool for estimation of field capacity and permanent wilting point in semiarid terrestrial ecosystem. Archives of Agronomy and Soil Science, 64 (9): 1240-1253.

Van Wambeke, A. R., 2000. The newhall simulation model for estimating soil moisture and temperature regimes. Department of Crop and Soil Sciences. Cornell University, Ithaca, NY. USA.

Wilding, L.P., 1985. Spatial variability: Its Documentation, Accommodation and Implication to Soil Surveys, 166-194p. In D.R. Nielsen and J. Bouma (eds.). Soil Spatial Variability: Pudoc, Wageningen, Netherlands.

Wilding, L.P., Bouma, J. Goss, D.W., 1994. Impact of spatial variability on interpretative modelling. in: quantitative modelling of soil forming processes R.B. Bryant, Arnold R.W. (Ed.) SSSA Special Publication Number 39, SSSA, Inc. Madison Wisconsin,USA. 